\title{
Templated synthesis of mesoporous titanium phosphates for the sequestration of radionuclides
}

\author{
X. Shari Li, Andrea R. Courtney, Wassana Yantasee, Shas V. Mattigod, Glen E. \\ Fryxell* \\ Pacific Northwest National Laboratory \\ P.O. Box 999 \\ Richland, WA \\ 99352 USA. \\ Fax: (509) 375-2186 \\ Tel: (509) 375-3856 \\ E-mail: glen.fryxell@pnl.gov
}

For submission to Inorganic Chemistry Communications

Several mesoporous titanium phosphate phases, with varying pore sizes, were prepared using non-ionic surfactants and easily handled titanium precursors under mild reaction conditions. Preliminary testing reveals that these materials have high affinity for certain radionuclides of environmental concern.

Significant amounts of radioactive waste have built up over the last half century as the result of nuclear weapons production and the accumulation of spent nuclear fuel. Ultimately, after processing, this waste is targeted to be buried in a deep geological repository. One plan is to include "getter materials" in with this waste in order to sequester any radionuclides that might leak from the wasteforms. Of particular interest in this regard are the long-lived actinide species (e.g. $\mathrm{Pu}, \mathrm{Am}, \mathrm{Np}$, etc.) and the anions (e.g. pertechnetate, iodide, etc.). These getter materials must be able to survive long-term exposure to elevated temperatures $\left(>150^{\circ} \mathrm{C}\right)$ and moderately high radiation fluxes. Due to their frailty towards radiolytic degradation, organic components cannot be used for either structure or function in the final getter material.

Since the first layered titanium phosphates were prepared 40 years ago, there has been interest in using this class of compounds as ion-exchange media, ${ }^{1}$ and layered metal phosphates continue to be of interest. ${ }^{2}$ Recently, microporous metal phosphates have also garnered attention for ion-exchange applications. ${ }^{3}$ In a related vein, open framework, porous titanium phosphate structures have been prepared by incorporating organic amines into the crystal lattice. ${ }^{4-6}$ Since the discovery of surfactant template mesoporous ceramic structures, 7,8 a great deal of effort has been expended studying the synthesis of mesoporous materials derived from this route. The synthesis of surfactant templated mesoporous titanium phosphate has been reported. ${ }^{9,10}$ These approaches have used cationic quaternary ammonium salt surfactants (ODTMAC ${ }^{9}$ and $\mathrm{CTAB}^{10}$ ), as well as anionic sulfonate surfactants (e.g. $\operatorname{SDS}^{9}$ ). The use of CTAB as surfactant resulted in surface areas of $240-340 \mathrm{~m}^{2} / \mathrm{g}$, and pore sizes of $35-38 \AA^{10}$. The use of ODTMAC as surfactant resulted in a surface area of $548 \mathrm{~m}^{2} / \mathrm{g}$, and a pore diameter of $31 \AA$. $^{9}$ This last material was found to have an anion exchange capacity of $5.41 \mathrm{mmole} / \mathrm{g}$ by $\mathrm{AgNO}_{3}$ titration. ${ }^{9}$ 
Our aim was to develop methodology that would provide similar mesoporous titanium phosphate phases using polymeric non-ionic surfactants, which create larger pores, thicker pore walls, and are easily removed by calcination at much lower temperatures $\left(200-300^{\circ} \mathrm{C}\right)$ than those typically employed for removal of the quaternary ammonium salts $\left(>500^{\circ} \mathrm{C}\right)$. For "getter" applications, the thicker walls are anticipated to deliver greater thermal stability, while larger pores are may be of value for enhanced mass transfer. This communication summarizes our efforts to make such mesoporous titanium phosphate phases.

Our first effort utilized the polymeric surfactant Pluronic P123 $\left(\mathrm{HO}\left(\mathrm{CH}_{2} \mathrm{CH}_{2} \mathrm{O}\right)_{20}\left(\mathrm{CH}_{2} \mathrm{CH}\left(\mathrm{CH}_{3}\right) \mathrm{O}\right)_{70}\left(\mathrm{CH}_{2} \mathrm{CH}_{2} \mathrm{O}\right)_{20} \mathrm{H}\right.$, from BASF), in conjunction with $\mathrm{Ti}(i \text {-PrO })_{4}$ and $85 \% \mathrm{H}_{3} \mathrm{PO}_{4}$, buffered with $1 \mathrm{M} \mathrm{NH} \mathrm{N}_{4} \mathrm{OH}$ to a nominal $\mathrm{pH}$ of 4 . The ratio of surfactant to metal was 0.0343 . The reaction mixture was stirred overnight at ambient temperature and then aged at $40^{\circ} \mathrm{C}$ for 71 hours. The product was collected by filtration and washed with DI water. Soxhlet extraction of the P123 template with refluxing ethanol for 24 hours produced a mesoporous phase with a surface area of $124 \mathrm{~m}^{2} / \mathrm{g}$ and $42 \AA$ pores. The presence of a significant $\mathrm{C}-\mathrm{H}$ stretching band in the FTIR absorbance spectrum of the product revealed the presence of residual surfactant within the mesopores.

Calcination of the as-synthesized material at $200^{\circ} \mathrm{C}$ for 4 hours produced a material with a surface area of $107 \mathrm{~m}^{2} / \mathrm{g}$ and $42 \AA$ pores. Increasing the calcination temperature to $350^{\circ} \mathrm{C}$ produced a material with a surface area of $131 \mathrm{~m}^{2} / \mathrm{g}$ and $40 \AA$ pores. FTIR analysis revealed no residual C-H stretching bands in the product after the higher temperature calcination.

In an effort to create a larger pore structure, the reaction was carried out using Tergitol 15-S-9 in place of the P123 surfactant. Using a similar procedure to that described above (except that the surfactant to metal ratio was increased to 0.343 ), and subjecting the crude product to Soxhlet extraction with refluxing ethanol for 24 hours produced a mesoporous material with a surface area of $206 \mathrm{~m}^{2} / \mathrm{g}$ and $45 \AA$ pores. Once again, there was evidence of residual organic materail left behind in the pores.

Replacing the Soxhlet extraction stage with calcination at $200^{\circ} \mathrm{C}$ for 4 hours produced a mesoporous material with $188 \mathrm{~m}^{2} / \mathrm{g}$ and $50 \AA$ pores. Increasing the calcination temperature to $350^{\circ} \mathrm{C}$ (4 hours) resulted in a mesoporous titanium phosphate with $223 \mathrm{~m}^{2} / \mathrm{g}$ and $45 \AA$ pores.

Chelated titanium complexes allow the titanium sol-gel syntheses to be carried out under mild conditions. Ammonium titanium lactate solution ("Tyzor") is an easily handled, commercially available titanium synthon that allows for controlled templated synthesis of mesoporous titanium phosphate at near-neutral pH's. Attempts to generate mesoporous structure templated with either P123 or Tergitol 15-S-9 using Tyzor at neutral $\mathrm{pH}$ failed. However, when the synthesis was carried out using cetyl trimethylammonium chloride $(\mathrm{CTAC}$ ) as the template (surfactant to metal ratio $=0.62$ ), a mesostructured product was generated. Calcination at $350^{\circ} \mathrm{C}$ for 4 hours produced a mesoporous titanium phosphate with a surface area of $340 \mathrm{~m}^{2} / \mathrm{g}$ and $40 \AA$ pores. Once again, there was evidence of residual organic material left behind in the pores, so this material was subjected to a second calcination, this time at $450^{\circ} \mathrm{C}$ for 4 hours. The resulting product had a surface area of $425 \mathrm{~m}^{2} / \mathrm{g}$ and $35 \AA$ pores. (Note that his is higher surface area than previously reported for CTAB.) 
Similar reactions were carried out using Tergitol and microwave heating (MARS 5 Microwave, $100 \%$ power, $300 \mathrm{~W}$ ), it was found that the reaction was complete in 15 minutes. The low angle XRD pattern was much cleaner, and the peak associated with the mesostructure was much sharper, suggesting a more uniform structure, with fewer defects in the wall structure.

XRD analysis of these materials provided no indication of any of the known crystalline titanium phosphate phases. In a couple of instances, weak, poorly defined patterns similar to anatase or brookite were observed. We interpret this to indicate small particles of the oxide phases imbedded in an amorphous matrix of mesoporous titanium phosphate. At no point did we observe any evidence of the crystalline titanium phosphate phases.

In order to evaluate the ability of these materials to sequester radionuclides, preliminary batch contact studies were carried out with these materials using a stock solution of ${ }^{239} \mathrm{Pu}(\mathrm{IV})$ nitrate in $0.1 \mathrm{M} \mathrm{HNO}_{3}$ and $0.1 \mathrm{M} \mathrm{NaNO}_{3}$. Equilibrium was achieved in approximately 20-30 minutes at a solution/solids ratio of 100 , so a batch contact time of 2 hours was used to insure that these values represent true equilibrium conditions. Under these conditions, all of these mesoporous titanium phosphates demonstrated good affinity for $\mathrm{Pu}(\mathrm{IV})$, typically removing $>95 \%$ of the $\mathrm{Pu}(\mathrm{IV})$ from a $2000 \mathrm{dpm} / \mathrm{mL}$ solution. Distribution coefficients $\left(\mathrm{K}_{\mathrm{d}}\right)$ are defined as a mass-weighted partition coefficient. $K_{d}$ values were typically in the range of $2,000-6,000 \mathrm{ml} / \mathrm{g}$, with individual measurements as high as $16,000 \mathrm{ml} / \mathrm{g}$ being observed for the material made using Tyzor and Tergitol. At a solution to solids ratio of 100 , a $\mathrm{Kd}$ value of $16,000 \mathrm{ml} / \mathrm{g}$ indicates that at equilibrium there was 160 times as much $\mathrm{Pu}(\mathrm{IV})$ in the mesoporous metal phosphate phase as there was remaining in the supernantant solution. This means that over $99 \%$ of the $\mathrm{Pu}(\mathrm{IV})$ was bound within the mesoporous titanium phosphate phase.

$\mathrm{Np}(\mathrm{V})$ is particularly difficult to bind, and is particularly mobile in the environment, making it a primary target for remediation efforts. ${ }^{236} \mathrm{~Np}(\mathrm{~V})$ binding studies were carried out using a $1000 \mathrm{dpm} / \mathrm{mL}$ initial concentration, in a matrix of $0.002 \mathrm{M}$ $\mathrm{NaHCO}_{3}$ (to mimic the groundwater conditions of a representative repository). Most of these mesoporous titanium phosphates showed good affinity for binding $\mathrm{Np}$. The mesoporous titanium phosphate made using Tergitol, microwave heating, and calcination at $250^{\circ} \mathrm{C}$ for 4 hours, demonstrated a very good affinity for $\mathrm{Np}(\mathrm{V})$ with a $\mathrm{Kd}$ of approximately $8,000 \mathrm{ml} / \mathrm{g}$, revealing that $>98 \%$ of the $\mathrm{Np}$ was esequestered by this material. This is particularly noteworthy for this difficult target.

In summary, this work has shown that it is possible to prepare mesoporous titanium phosphate using a variety of surfactant templates and titanium chelates (Tyzor) as reagents. This work has also shown that these reactions can be acclerated considerably by using microwave heating instead of conventional heating methods. Soxhlet extraction using ethanol was not effective for surfactant removal in these materials. Lower calcination temperatures resulted in significant amounts of residual organic material left behind in the pores. Calcination at $350^{\circ} \mathrm{C}$ seems to be sufficient for P123 and Tergitol, but CTAC requires $450^{\circ} \mathrm{C}$ to burn off all of the template. In general, Tergitol gave higher surface areas than did P123, and the highest surface areas were provide by CTAC. The different calcination temperatures seem to have little impact on pore size. These mesoporous titanium phosphates clearly have promise as radionuclide sorbent materials, 
and are particularly noteworthy for their ability to sequester $\mathrm{Np}(\mathrm{V})$. The complete details of these sorbent studies will be reported in due course.

This research was supported by the U. S. Department of Energy (DOE), Office of Civilian Radioactive Waste Management. This work was performed at Pacific Northwest National Laboratories, which is operated for the DOE by Battelle Memorial Institute under contract DE AC06-76RLO 1830.

\section{Notes and references}

1. A. Clearfield and J. A. Stynes, J. Inorg. Nucl. Chem. 1964, 26, 117.

2. H. J. Sue, K. T. Gam, N. Bestaoui, N. Spurr and A. Clearfield, Chem. Mater. 2004, 16, 242-249.

3. C. V. Krishnamohan Sharma, C. C. Chusei, R. Clérac, T. Möller, K. R. Dunbar, and A. Clearfield, Inorg. Chem. 2003, 42, 8300-8308.

4. Y. Liu, Z. Shi, Y. Fu, W. Chen, B. Li, J. Hua, W. Liu, F. Deng and W. Pang, Chem. Mater. 2002, 14, 1555-1563.

5. Y. Liu, Z. Shi, L. Zhang, Y. Fu, J. Chen, B. Li, J. Hua and W. Pang, Chem. Mater. 2001, 13, 2017-2022.

6. S. Ekambaram and S. C. Sevov, Ang. Chem. Int. Eng. Ed. 1999, 38, 372-375.

7. C. T. Kresge, M. E. Leonowicz, W. J. Roth, J. C. Vartuli and J. S. Beck, Nature, 1992, 359, 710-712.

8. J. S. Beck, J. C. Vartuli, W. J. Roth, M. E. Leonowicz, C. T. Kresge, K. D. Schmitt, C. T.-W. Chu, D. H. Olson, E. W. Sheppard, S. B. McCullen, J. B. Higgins and J. L.

Schlenker, J. Am. Chem. Soc. 1992, 114, 10834-10842.

9. A. Bhaumik and S. Inagaki, J. Am. Chem. Soc. 2001, 123, 691-696.

10. E. Rodriguez-Castellon, J. Jimenez-Jimenez, A. Jimenez-Lopez, P. Marireles-Torres, J. R. Ramos-Barrado, D. J. Jones, J. Roziere, Solid State Ionics 1999, 125, 407-410. 